\title{
The Object-oriented Programming Teaching Around Class as the Center
}

\author{
Yue $\mathrm{Gao}^{1, \mathrm{a}}$, Bin $\mathrm{Li}^{2, \mathrm{~b}}$, Shuying Zhang ${ }^{1, \mathrm{c}}$ \\ 1 College of Computer Science and Technology, Beihua University jilin, 132013, China \\ ${ }^{2}$ Farm Machinery Station, Chaluhe Town, Yongji CountyJilin, 132014,China \\ aemail: lunagao@126.com, bemail: jilinlib@126.com @163.com, cemail: jlzhangsy@126.com
}

Keywords: -Object-oriented programming; C++; Teaching; Class

\begin{abstract}
The Object-oriented programming is a professional foundation courses which is generally set up in the university, and it is the first lesson of a lot of follow-up courses. It runs through the other subjects of the teaching system. It is particularly important to learn this language for learning other courses in the future. In this paper, the characteristics, the course content, the teaching method of the $\mathrm{C}++$ course are studied. The teaching ideas of Class as the core is proposed, fully around the class, closely linked to the design main line of the class in the process of teaching $\mathrm{C}++$, to enhance the concept of class, around the design of the class teaching. Thereby, it can enhance teaching quality and teaching effectiveness of the $\mathrm{C}++$ programming. Practice has proved that the teaching methods have a good teaching effect for students to learn and understand object-oriented thinking and raise the students' practical programming skills.
\end{abstract}

\section{Introduction}

The object-oriented programming is a professional foundation courses which is generally set up in the university, and it is the first lesson of a lot of follow-up courses. It runs through the other subjects of the teaching system. It is particularly important to learn this language for learning other courses in the future. For a long time, it is considered to be one of the computer professional languages which are very difficult to master[1][2]. It has a large gap between this teaching effect and object-oriented programming design ideas. The students only remember a few simply object-oriented statements, and can not design the object-oriented programs after learning $\mathrm{C}++[3]$. The thinking way of $\mathrm{C}++$ programming programmed is no longer a sequence of steps for functional, But a feature elements and participate objects that completed a function in the object. It tends to simulate real-world, these two concepts of classes and objects is proposed. We will divide the actual existence of things in reality world by class. Things in a class have the same properties. We use objects to describe these specific things[4]. Therefore, through years of teaching, I think that the core of $\mathrm{C}++$ is the concept of classes and Objects. Only by fully around the class, closely linked to the design main line of the class in teaching $\mathrm{C}++$, to enable students to really grasp the idea of object-oriented programming. To learn a language class the most important is to learn the ideas and methods of its programming. Do not rigidly adhere to the syntax details, but from a higher level grasp of $\mathrm{C}++[5]$.

In the second section of this paper, author introduces The characteristics of $\mathrm{C}++$ language; Teach students in accordance with their aptitude, select appropriate textbook is in the 3rd section, Around the class, through the example introduced each knowledge point in the 4th section. Focus on the practical aspects to improve teaching effectiveness in the 5th section. Practice programming ability in the 6th section. The last section is conclusion.

\section{The characteristics of $\mathrm{C}++$ language}

Abstract concept

$\mathrm{C}++$ is written based on $\mathrm{C}$ language, retained the function of the $\mathrm{C}$, and Added object-oriented concepts. The concept sounds very abstract and difficult. In fact, these elements are mechanisms to 
implement object-oriented concept in C, in other words, it is a means. This mean is able to complete the object-oriented features, without destroying the $\mathrm{C}$ function, but also to ensure the overall security. So let the students understand the reasons for the introduction of these mechanisms, abstract concepts in $\mathrm{C}++$ become concrete, and you can play a multiplier effect.

Rich in content.

The Basic concepts of $\mathrm{C}++$ object-oriented programming including: classes, objects, inheritance, encapsulation, overloading, polymorphism, etc. Around these concepts, we define the elements of a constructor, destructor, a combination of class, abstract class, concrete class, static member, friend, templates, virtual functions, pure virtual functions, I/O stream class and so on. Since the object-oriented nature is closer to a calculation model of human cognitive things. In specific programming process, we are not in a hurry to study the function, first analyzes the elements required to complete this function. Analog and describe each element with the program code to construct class, Interface to communicate between classes, using the principle of encapsulation to protect class internal. The inheritance and polymorphism makes the program more vivid simulation between classes, and more vividly simulate the real world. Program is no longer just the code line by line, build a truly functional model. In the teaching process, the design around the class, through the examples of these concepts and elements gradually introduced to the students.

Strong continuity of knowledge.

Knowledge of $\mathrm{C}++$ language with strong continuity, inter-related, The following contents based on Leading content, previous knowledge is not strong will lead to follow - up can not be done. For example, we only know the concept of classes and objects, Master the basic method of the class and object-oriented programming, to be able to continue to study the inheritance and derived. Only study the inheritance and derived in order to understand the concept of abstract class in the polymorphic. Therefore, in the study should be appropriate to review the previous knowledge, concepts learned if there do not understand, do not know, must know that before the next class, to do the learning coherence of the curriculum.

\section{Teach students in accordance with their aptitude, select appropriate textbook}

According to the level of students and teaching situations, Teachers choose the right materials. Try to choose a textbook that is written by the perennial C++ teachers. The materials should be easy to understand for the students, as soon as possible into the concept of class and object. Using the class as the main line, step-by-step describes the object-oriented thinking. For students, the new concept will take time to digest and absorb, oriented concepts introduced sooner, the more good results. The class is the fundamental mechanism of the $\mathrm{C}++$ language. It is a basic concept of object-oriented and is to achieve the organizational form of data encapsulation and information hiding. Therefore, the class is $\mathrm{C}++$ programming foundation. The level of understanding of the concept of class means the master degree of object-oriented programming. Through years of teaching and research, summed up, understanding of the class is the difficulties and the breakthrough point of learning the object-oriented programming in $\mathrm{C}++$ Teaching, The sooner the understanding and grasp of the notion of class, the students to learn more effectively. Only firmly around the class, using the class as the center step - by - step teaching, To be able to truly enable students to master the $\mathrm{C}++$ programming and Cultivate high-level $\mathrm{C}++$ programmers.

\section{Around the class, through the example introduced each knowledge point in $\mathrm{C}++$}

The same example is always used in the teaching process of $\mathrm{C}++$, This example from start to finish throughout the teaching process. First of all, the definition and description of a simple class is given. With the deepening of teaching, continue to join the new concepts and mechanisms, such as class combination, inheritance and derived, polymorphism, Templates, etc. It gradually formed a kind of system, eventually expanded into a complete $\mathrm{C}++$ software system. In the actual teaching process, specifically follow the following process, object-oriented knowledge is taught tightly around the concept of class. 
Introduced the concept of classes and objects

In teaching, first, from the classification concept of the nature to introduce the class, and then introduces object-oriented programming class. Its purpose is to teach students how to abstract concrete things, how to describe the same sort of things, and extracted common attributes and behavior of the similar things. Then through the design of a simple class, the class contains only data members and member functions, so that students understand the class is in two parts by the data members and function members. The data members is used to describe the properties of class, it is a kind of static characteristics. The function members is used to describe the behavior of class, it is the dynamic characteristics of the class. At the same time, the definition of packaging external interface and access properties is given. And then use the class to define the object, drawing off the concept of object creation and initialization, and call the function members through the object to accomplish the object initialization.

The introduction of constructor and destructor

The concept of object initialization leads to the constructor in teaching, and introduce the benefits of using a constructor. Here, it is needed to introduce the concept of function overloading, and given the concept of overloaded constructor, default constructor. And later, process of creating objects, the constructor function and Usage, memory space allocation are introduced. And then teach the object using the completed space release, and Leads to the concept of destructor. By way of example, teachers guide students to write a simple class using the constructor and destructor.

Inheritance and derived of class

Inheritance is the most important mechanism in object oriented programming. The benefits of inheritance are to simplify programming and implementation code reuse. Teachers can teach that many entities or concepts are not isolated in the real world, they have a common characteristic, but there are subtle differences. People describe the similarities and differences between these entities or concepts using hierarchical classification methods, Teachers guide students to build their own class family using inheritance, abstract base class, derived other derived class. When we introduce the inheritance concept of design class, we teach object-oriented to a peak, let the students try to use inheritance in class design as soon as possible.

Polymorphism .

Polymorphism is one of the basic characteristics of object-oriented programming. First, introduced the importance and benefits of polymorphism in program design, and then introduce the polymorphic definition. At the same time, teach virtual functions, pure virtual functions, abstract classes, and concrete classes etc. Taught Polymorphism problem is linked to compile and run.

Template

Template is a tool to support polymorphism in $\mathrm{C}++$, It is a simplified method of programming. Mastering the template design, we can design into a class to complete for only have different data types, the same thing treatment of other operations. Let students to see the benefits of the template, raise their interest, and learn to write their own function and class templates to simplify programming.

Operator Overloading

Let students learn to use the operator to conduct operations that the type of the operations is defined by themselves. In fact, $\mathrm{C}++$ operators are the functions of operators. The operator has the function returns. The function can be overloaded, operator can be overloaded. $\mathrm{C}++$ allows operator overloading, the programmer can give the operator a new meaning. It greatly expanded the $\mathrm{C}++$ computing power, so that $\mathrm{C}++$ is more powerful. Make good use of operator overloading, new data types can use the existing computing operator symbol. So we designed a class type is more in line to the basic data types.

The above is the basic sequence of teaching object-oriented concepts based on class as the core in $\mathrm{C}++$. Selecting the appropriate instance in the process of teaching, and expand the class design step by step. Let the students understand the concepts from the degree of the mechanisms, and stripping of its demystification, and grasp the object-oriented thought, and reach the learning objectives of their own independent programming. 


\section{Focus on the practical aspects to improve teaching effectiveness}

In practice, we can practice training for the students through classroom experiment, extracurricular experiment, curriculum design mode, and enable students to understand and master the basic content of $\mathrm{C}++$. Be able to independently write a program using object-oriented thinking, Independent debugging on the machine, Independent operation procedure and analysis results, Allow students has a comprehensive grasp to the whole process of object-oriented programming design.

Classroom experiment should be combined with the theory of teaching, and formulated corresponding experimental plan according to the theory knowledge of class teaching. It is to deepen and complement of the theoretical teaching. It is used to deep the understanding of theoretical knowledge, and to solve the questions of theoretical knowledge, develop students' initial program design capabilities.

Extracurricular experiment should be diversified. You can choose example, exercises in textbook. You can also set additional questions as homework according to the classroom experiment, let the student program and debug program, for non-priority content in the curriculum, also can be left to the students to think, and independently completed practical activities.

After the basic teaching of $\mathrm{C}++$ courses is accomplished, there is a two week curriculum design practice according to the curriculum arrangement. Practice contents of curriculum design is more complicated, relates to depth is more widely, the experimental value is more practical. It not only can help students master the $\mathrm{C}++$ main content, but also can cultivate students' practical problems analysis, write a program, independent operation Abilities. So that, you can accomplish the teaching task better.

In practice links, practical problems should associate with the class, consistent with the progress of the teaching, strengthen difficulty gradually. In this way, it can let the students understand, digest, master classes, eventually form their own knowledge system in practice.

\section{Conclusion}

The concept of class and object is the core of object-oriented program design. In C++ teaching, using the class as the core, fully around the class, closely linked to the design mainline of class, strengthen the concept of class, around the design of the class teaching. Thus, it can improve the quality of teaching and the teaching effect of $\mathrm{C}++$ program design. The teaching method has the very good teaching effect for students to learn and understand object-oriented thinking and cultivate students' ability to practice programming.

\section{Acknowledgement}

The research work is supported by Education and Science "12th Five-Year" Planned Project of Jilin Province (No.GH12076), Major Projects of Science and Technology Department of Jilin Province (No.20110360).

\section{References}

[1] Feng He, From Template to the Model: The Thinking of Object-oriented Program Design Teaching[J]. Journal of EEE, 2010, 32 (6): 64-66

[2] Hui Ma, Discussion on Teaching Methods of Object-Oriented Programming [J].Modern Computer, 2011(10): 59-61

[3] Su kui Lu, Sile Wang, From C to C++ Programming Model of the Rapid Transformation [J]. Coal Technology, 2010,29(10): 229-230.

[4] Ya Li Su, Using Case Study to Teach Core Concepts in Computer Program Design [J]. Journal of Yuxi Normal University ,2009,25(6): 65-69

[5] Hua Zhang, Xu Gao, The Using the Comparing Teaching Methods in the Program Design of C Plus Plus [J].Computer Knowledge and Technology, 2010,6(26):7306-7308 